\title{
Microwave Absorption and Shielding Property of Fe-Si-Al alloy/MWCNT/polymer Nanocomposites
}

\author{
Hoyeon Kimm ${ }^{a+}$, Seongeun Park ${ }^{a, b+}$, Sehyun Kim ${ }^{c^{*}}$ and Yongsok Seo ${ }^{a^{*}}$
}

${ }^{\text {a }}$ RIAM, School of Materials Science and Engineering, College of Engineering, Seoul National University, Kwanakro-1, Kwanak-gu, Seoul, 08826, Korea

${ }^{\mathrm{b}}$ Hyundai Mobis Technology Center, 17-2, Mabuk-ro, 240 beon-gil, Giheung-gu, Yongin-si, Gyeonggi-do, 16891, Korea

c Polymer Processing Technology Team, LG Chemical Ltd./Tech Center, Moonjidong 104-1, Yousungku, Daejon, 34114, Korea

*CORRESPONDING AUTHOR FOOTNOTE

E-mail: ysseo@snu.ac.kr Tel: +82-2-880-9085, Fax: +82-2-885-9671 


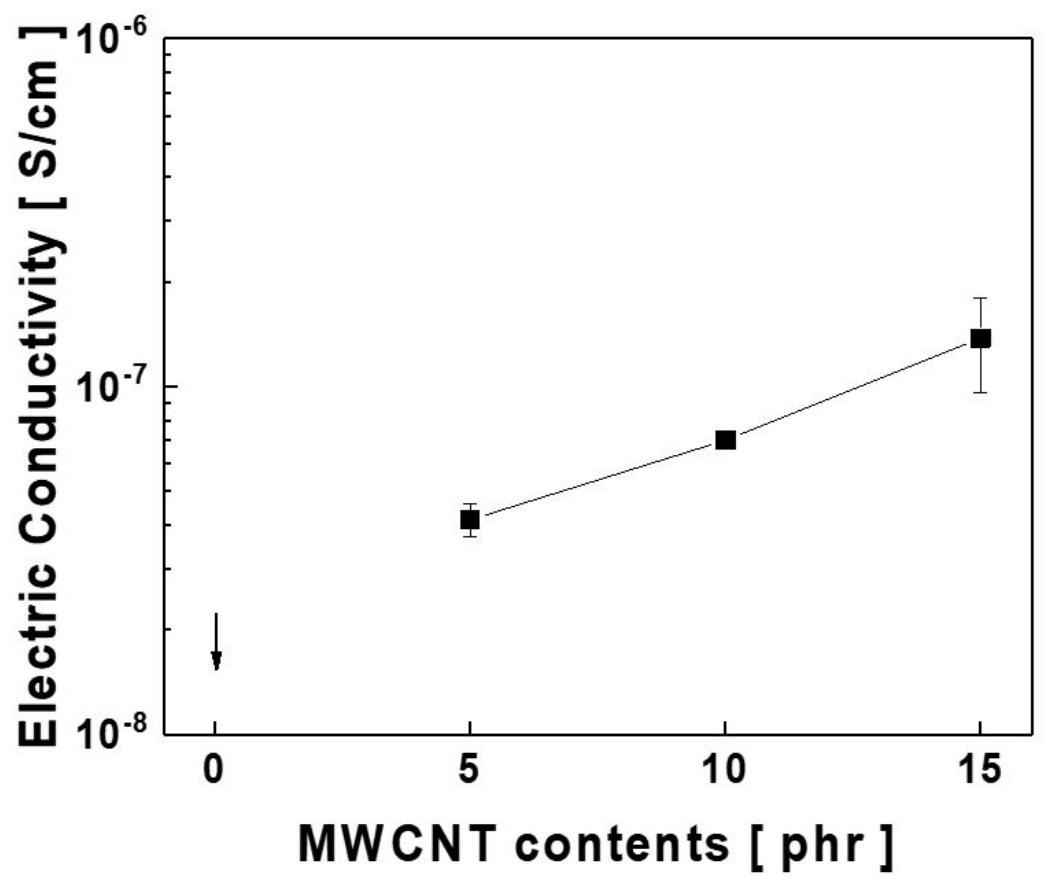

Figure S1. Electrical conductivity enhancement with the MWCNT addition. 